\title{
High expression of microRNA-1266 in hepatocellular carcinoma is associated with poor prognosis of patients and biological cell growth
}

\author{
XINHUI HUANG ${ }^{1 *}$, YONGPING LAI $^{2 *}$, NA YAO $^{3 *}$, YONGLIANG CUI $^{2}$, XIAOLING YU ${ }^{4}$, \\ ZHIXIONG CAI ${ }^{5}$, YUPENG TANG ${ }^{2}$, YAO HUANG ${ }^{2}$ and JINHUA ZENG ${ }^{2}$
}

Departments of ${ }^{1}$ Invasive Technology and ${ }^{2}$ Hepatopancreatobiliary Surgery, Mengchao Hepatobiliary Hospital of Fujian Medical University, Fuzhou, Fujian 350025; ${ }^{3}$ Department of Oncology, Fujian Medical University Union Hospital, Fuzhou, Fujian 350001; Departments of ${ }^{4}$ Pharmacy and ${ }^{5}$ Hepatobiliary Technology Key Laboratory, Mengchao Hepatobiliary Hospital of Fujian Medical University, Fuzhou, Fujian 350025, P.R. China

Received July 17, 2020; Accepted December 17, 2020

DOI: $10.3892 / 01.2021 .12608$

\begin{abstract}
Hepatocellular carcinoma (HCC) is a cancer with a poor prognosis and a low survival rate. Previous studies have found that microRNA-1266 (miR-1266) is associated with tumorigenesis and progression of several types of cancer, such as breast cancer and gastric cancer. The aim of the present study was to investigate the effects of miR-1266 on the clinical prognosis and biological behavior of HCC. For this purpose, reverse transcription-quantitative $\mathrm{PCR}$ was used to detect the expression of miR-1266 in HCC tissues and HCC cell lines. In addition, Kaplan-Meier survival analysis and Cox regression analysis were used to evaluate the prognostic value of miR-1266. Cell Counting Kit-8 (CCK-8) and Transwell assays were used to analyze the effect of miR-1266 on the biological behavior of cells. The aforementioned assays demonstrated that the examined HCC tissues had a significant upregulation of miR-1266 expression compared with normal tissues $(\mathrm{P}<0.001)$. The overexpression of miR-1266 was significantly associated with Tumor-Node-Metastasis stage $(\mathrm{P}=0.014)$. The results of the Kaplan-Meier analysis indicated that the 5-year overall survival rate of patients with high expression of miR-1266 was significantly lower compared with patients with low expression
\end{abstract}

Correspondence to: Dr Xinhui Huang, Department of Invasive Technology, Mengchao Hepatobiliary Hospital of Fujian Medical University, 312 Xihong Road, Fuzhou, Fujian 350025, P.R. China

E-mail: xindaoom@163.com

Dr Yongliang Cui, Department of Hepatopancreatobiliary Surgery, Mengchao Hepatobiliary Hospital of Fujian Medical University, 312 Xihong Road, Fuzhou, Fujian 350025, P.R. China

E-mail: cuiyl_fmu@163.com

*Contributed equally

Key words: hepatocellular carcinoma, microRNA-1266, prognosis, biological behaviors of miR-1266 $(\mathrm{P}=0.015)$. Cox regression analysis demonstrated that the expression level of miR-1266 could be used as an independent prognostic factor of HCC. CCK-8 and Transwell assays demonstrated that overexpression of miR-1266 promoted the proliferation, migration and invasion of HCC cells. In summary, the findings of the present study indicated that high expression of miR-1266 was positively associated with poor prognosis of patients with $\mathrm{HCC}$ and promoted cell proliferation, migration and invasion of HCC cells. miR-1266 may be used as a biomarker for HCC prognosis.

\section{Introduction}

Hepatocellular carcinoma (HCC) is one of the most common cancer worldwide, with similar rates of incidence and mortality $(1,2)$. As the third most common cause of cancer-related death, HCC leads to $>60,000$ deaths globally each year $(3,4)$. The majority of patients with $\mathrm{HCC}$ are already in advanced stages when they are diagnosed, and the most effective treatment for early-stage patients is surgical resection (5). However, the long-term survival rate of patients with $\mathrm{HCC}$ is low, and the prognosis is poor due to the high rate of $\mathrm{HCC}$ recurrence and metastasis so resection is not available for most patients (6). Due to changes in lifestyle and environment, $\mathrm{HCC}$ is currently demonstrating a trend of continuously increasing global incidence that seriously affects quality of life (7). Numerous types of antitumor therapy, such as radiotherapy, chemotherapy and adjuvant therapy have been used for HCC, however, there are few specific markers for the diagnosis and prognosis of HCC to date (8). It is important to identify effective targets for early detection, treatment, and prognostic monitoring of patients with $\mathrm{HCC}$; hence, it is necessary to identify new biomarkers (9).

MicroRNAs (miRNAs) are a major class of small non-coding RNAs consisting of $\sim 18-25$ nucleotides that were originally identified in Caenorhabditis elegans and negatively regulate gene expression at the mRNA level (10-12). Numerous studies have revealed the important role of miRNAs in biological processes, such as cell proliferation and 
differentiation, embryogenesis, metabolism, organogenesis and apoptosis (12-14). Growing evidence indicates that miRNAs are altered in a number of diseases, including cardiovascular diseases, hepatitis and various types of cancer including prostate cancer and osteosarcoma due to genomic events, such as gene mutations or downregulation caused by enzymes that involved in miRNAs biogenesis (15-17). Previous studies have demonstrated that miR-29a, miR-21 and miR-221 and 222 are abnormally expressed in HCC (18-21). Shi et al (22) recently found that 29 miRNAs, including miR-1266, were upregulated in the tissues of patients with HCC. It can be concluded from previous studies that miR-1266 may serve an important role in the occurrence and development of HCC. However, the expression pattern, biological function and clinical significance of miR-1266 in the pathogenesis of HCC remain unclear.

The present study aimed to investigate the difference in miR-1266 expression between HCC and normal liver tissues and evaluated the clinical prognostic significance of miR-1266 in patients with HCC. In addition, the effects of miR-1266 on the proliferation, migration and invasion of HCC cell lines were also investigated. The present study aimed to provide a new biomarker for HCC.

\section{Materials and methods}

Patients and specimens. A total of 119 patients (median age, 60 years; age range, 26-77 years) with HCC admitted to Mengchao Hepatobiliary Hospital of Fujian Medical University (Fuzhou, China) between January 2012 and December 2014 were included in this study. HCC tissue and normal adjacent tissues [all were confirmed by at least two pathologists of Mengchao Hepatobiliary Hospital of Fujian Medical University (Fuzhou, China)] $5 \mathrm{~cm}$ away from the cancer lesion were collected from each patient. The tissue samples were immediately frozen in liquid nitrogen at $-80^{\circ} \mathrm{C}$ until subsequent total RNA extraction experiments were performed. All patients underwent resection surgery and did not receive any treatment, such as chemotherapy and radiotherapy before surgery. The exclusion criteria were as follows: i) Patients with no complete follow-up data; ii) patients suffering from other types of cancer; and iii) patients with systemic intolerance to surgery. In order to collect the overall survival outcome information of patients with HCC, all of them were enrolled in the 5-year follow up investigation by telephone. The follow-up was performed at intervals of 3 months during the first 2 years, 6 months in years 2-4 and annually in the last year. The results of the follow up are listed in Table I. Each patient signed a written consent approving the use of their tissues for research purposes after the operation. The present study was approved by the Research Ethics Committee of Mengchao Hepatobiliary Hospital of Fujian Medical University (approval no. 2012-032-01; Fuzhou, China).

Cell lines and transfection. In total 4 types of HCC cell lines (Hep3B, Huh-7, MHCC97 and SNU-387) and one normal human liver cell line MIHA were purchased from Shanghai Cell Bank of the Chinese Academy of Sciences. In Hep3B cells there are obvious granular endoplasmic reticulum pools and mitochondria; ring-shaped lamellar accumulation and glycogen aggregates are found in the cytoplasm, and $\alpha$-fetoprotein (AFP) is positive (23). HuH-7 cells are flat polygonal in the early stage with fine particles in the cytoplasm, while later cells are elongated in the form of coarse particles (24). MHCC97 cells grow into dense colonies or single-layer flakes with a doubling time of about $31 \mathrm{~h}$ presenting a typical malignant epithelial morphology, and AFP is positive (25). The SNU-387 cell line demonstrates adherent cell growth and obvious nuclear convolution (26). The Hep3B, Huh-7 and MHCC97 cells were cultured in DMEM medium (Gibco; Thermo Fisher Scientific, Inc.) supplemented with 10\% FBS (Gibco; Thermo Fisher Scientific, Inc.), while the MIHA and SNU-387 cells were cultured in RPMI 1640 medium (Gibco; Thermo Fisher Scientific, Inc.) supplemented with $10 \%$ FBS. All cells were cultured at $37^{\circ} \mathrm{C}$ in a humidified incubator with $5 \% \mathrm{CO}_{2}$.

Cells $\left(2 \times 10^{5}\right)$ were seeded into a 6 -well plate before transfection. According to the manufacturer's instructions, miR-1266 mimic (5'-CCUCAGGGCUGUAGAACA GGGCU-3'), scrambled mimic negative control (mimic NC; 5'-UUCUCCGAACGUGUCACGUTT-3'), miR-1266 inhibitor (5'-AGCCCUGUUCUACAGCCCUGAGG-3') and scrambled inhibitor NC (5'-CAGUACUUUUGUGUAGUA CAA-3') (Shanghai GenePharma Co., Ltd.) all at a final concentration of $50 \mathrm{nM}$ were transfected into cells by using Lipofectamine $^{\circledR} 2000$ Reagent (Invitrogen; Thermo Fisher Scientific, Inc.) in serum-free condition for $6 \mathrm{~h}$ at $37^{\circ} \mathrm{C}$ and then complete DMEM medium was added. Transfection efficiency was measured after $24 \mathrm{~h}$ of transfection at $37^{\circ} \mathrm{C}$ and then the transfected cells were used in subsequent experimentation. Untreated cells served as the blank control group.

$R N A$ extraction and reverse transcription-quantitative $(R T-q) P C R$ analysis. Total RNA of tissues or cell lines was extracted using TRIzol ${ }^{\circledR}$ reagent (Takara Bio Inc.) according to the manufacturer's instructions. The DNA was removed from the extracted total RNA by trypsin and then RNA concentration was detected by NanoDrop. Complementary DNA (cDNA) was obtained by reverse transcription from the extracted RNA using the cDNA Reverse Transcription kit (Applied Biosystems; Thermo Fisher Scientific Inc.) with incubation at $16^{\circ} \mathrm{C}$ for $30 \mathrm{~min}$, then $42^{\circ} \mathrm{C}$ for $30 \mathrm{~min}$ and terminated at $85^{\circ} \mathrm{C}$ for $5 \mathrm{~min}$. Relative expression of miR-1266 was assessed in cell lines and tissues using the SYBR Green I Real-Time PCR kit (Shanghai GenePharma Co. Ltd.) on an Applied Biosystems 7900 Real-Time PCR system (Applied Biosystems; Thermo Fisher Scientific Inc.) using the following thermocycling conditions: Preliminary denaturation at $95^{\circ} \mathrm{C}$ for $2 \mathrm{~min}$, then $35 \mathrm{cycles}$ of $94^{\circ} \mathrm{C}$ for $30 \mathrm{sec}, 60^{\circ} \mathrm{C}$ for $30 \mathrm{sec}$, followed by $72^{\circ} \mathrm{C}$ for $45 \mathrm{sec}$. The sequences used in RT-qPCR were as follows: miR-1266 forward, 5'-GCCGAGCCTCAG GGCTGTAGA-3', reverse, 5'-CTCAACTGGTGTCGT GGA-3'; U6 forward, 5'-GCTTCGGCAGCACATATACTA AAAT-3' and reverse 5'-CGCTTCACGAATTTGCGTGTC AT-3'. U6 small nuclear RNA was used for normalization and relative quantification of $\mathrm{miR}-1266$ expression was calculated by using the $2^{-\triangle \Delta C q}$ method (27). Each sample measurement was performed in triplicate.

Cell proliferation assay. Cell proliferation was assessed by using the Cell Counting Kit- 8 assay (CCK-8; Dojindo Molecular Technologies, Inc.) according to the manufacturer's 
Table I. Association between miR-1266 expression and clinical characteristics of patients with hepatocellular carcinoma $(n=119)$.

\begin{tabular}{|c|c|c|c|c|}
\hline \multirow[b]{2}{*}{ Characteristics } & \multirow[b]{2}{*}{$\begin{array}{l}\text { No. of } \\
\text { patients }\end{array}$} & \multicolumn{2}{|c|}{$\begin{array}{l}\text { miR-1266 } \\
\text { expression }\end{array}$} & \multirow[b]{2}{*}{ P-value } \\
\hline & & $\begin{array}{l}\text { Low } \\
(n=57)\end{array}$ & $\begin{array}{l}\text { High } \\
(n=62)\end{array}$ & \\
\hline Age, years & & & & 0.655 \\
\hline$<60$ & 58 & 29 & 29 & \\
\hline$\geq 60$ & 61 & 28 & 33 & \\
\hline Sex & & & & 0.584 \\
\hline Female & 45 & 23 & 22 & \\
\hline Male & 74 & 34 & 40 & \\
\hline AFP, ng/ml & & & & 0.060 \\
\hline$<20$ & 50 & 29 & 21 & \\
\hline$\geq 20$ & 69 & 28 & 41 & \\
\hline Tumor size, cm & & & & 0.066 \\
\hline$<5$ & 69 & 38 & 31 & \\
\hline$\geq 5$ & 50 & 19 & 31 & \\
\hline HBV infection & & & & 0.087 \\
\hline Absent & 55 & 31 & 24 & \\
\hline Present & 64 & 26 & 38 & \\
\hline Cirrhosis & & & & 0.105 \\
\hline Absent & 66 & 36 & 30 & \\
\hline Present & 53 & 21 & 32 & \\
\hline TNM stage & & & & 0.014 \\
\hline I-II & 88 & 48 & 40 & \\
\hline III-IV & 31 & 9 & 22 & \\
\hline
\end{tabular}

miR, microRNA; TNM, Tumor-Node-Metastasis; HBV, hepatitis B virus; AFP, $\alpha$-fetoprotein.

instructions. HCC Huh-7 and MHCC97H cells (1x10³/well) were seeded into a 96 -well culture plate at $7^{\circ} \mathrm{C}$ for $24 \mathrm{~h}$ after transfection. Then, the CCK- 8 solution was added to each well for $0,24,48$, and $72 \mathrm{~h}$ and incubated for $2 \mathrm{~h}$. The absorbance was analyzed at $450 \mathrm{~nm}$ using a microplate reader (Thermo Fisher Scientific, Inc.). Each sample measurement was performed in triplicate at each time point.

Cell migration and invasion assay. Migration and cell invasion assays were performed using the Transwell chamber (BD Biosciences) with $8-\mu \mathrm{m}$ pores. The cells were inoculated in serum-free DMEM medium after transfection. In the invasion assay, Matrigel (Becton-Dickinson and Company) was pre-coated on the bottom layer of the upper chamber at $37^{\circ} \mathrm{C}$ for $4 \mathrm{~h}$, but Matrigel was not added in the upper chamber of the migration assay. Huh-7 and MHCC $97 \mathrm{H}$ cell suspension $\left(5 \times 10^{4}\right.$ cells/well) was added into the upper chamber and $600-800 \mu 1$ of medium containing $10 \%$ FBS as a chemokine was added into the lower chamber. After $24 \mathrm{~h}$ of incubation at $37^{\circ} \mathrm{C}$, the bottom membrane of the upper chamber was fixed in methanol for $30 \mathrm{~min}$ at room temperature, and then stained with $0.1 \%$ crystal violet for $15 \mathrm{~min}$ at room temperature. After air-drying, the stained cells were mounted with neutral resin and counted under a light microscope.

Luciferase reporter assay. First, it was predicted that DAB2 Interacting Protein (DAB2IP) may be the target gene of miR-1266 through TargetScan (http://www.targetscan.org/ vert_71/). The wild-type (WT) and mutant (MUT) promoters of DAB2IP were constructed by Shanghai GenePharma Co. Ltd. and inserted into the pGL3 basic vector (Promega Corporation). The DAB2IP 3'-untranslated region (3'-UTR) sequence was amplified from normal human genomic DNA and subcloned into the pmirGLO luciferase reporter vector (Promega Corporation). MHCC97 cells were cultured in a 24-well plate, and after $24 \mathrm{~h}$ of culture, they were co-transfected with WT or MUT 3'-UTR vector and miR-1266 mimic, 5'-CCU CAGGGCUGUAGAACAGGGCU-3'; mimic NC, 5'-UUC UCCGAACGUGUCACGUTT-3'; miR-1266 inhibitor, 5'-AGC CCUGUUCUACAGCCCUGAGG-3' or inhibitor NC, 5'-CAG UACUUUUGUGUAGUACAA-3' using Lipofectamine ${ }^{\circledR} 2000$ reagent (Invitrogen; Thermo Fisher Scientific, Inc.). Following $24 \mathrm{~h}$ of transfection, luciferase activity was measured by the dual luciferase reporter gene assay system (Promega Corporation) according to the manufacturer's instructions. The relative luciferase activity was estimated by normalizing the luciferase activity to the Renilla luciferase activity. All assays were repeated three times.

Statistical analysis. All biological experiments were repeated at least 3 times and statistical analyses were performed using SPSS 19.0 software (IBM Corp.) and GraphPad Prism 7.0 software (GraphPad Software Inc.). By using mean value of miR-1266 expression (0.8732) as the cut-off value, patients were divided into high miR-1266 expression group and low miR-1266 expression group. $\chi^{2}$ test was used for assessing the association between miR-1266 expression and clinical features of patients. The difference between two groups were analyzed using paired Student's t-test. Multiple comparisons were performed using one-way ANOVA followed by the post hoc Tukey's test. Kaplan-Meier analysis and log-rank test were used to test the overall survival rate of patients, and the prognostic significance of miR-1266 was evaluated by Cox regression analysis. Data are presented as the mean \pm standard deviation. $\mathrm{P}<0.05$ was considered to indicate a statistically significant difference.

\section{Results}

Expression of miR-1266 in HCC tissues and cell lines. Firstly, the expression of miR-1266 in 119 pairs of HCC tissues and adjacent normal liver tissues was assessed. The results indicated that the miR-1266 expression level was significantly higher in the HCC tissues compared with the adjacent normal tissues $(\mathrm{P}<0.001$; Fig. 1A). In addition, further analysis of miR-1266 expression in HCC cell lines (Hep3B, Huh-7, MHCC97 and SNU-387) was performed. The expression of miR-1266 in the HCC cell lines was significantly higher compared with that of the normal cell line MHA $(\mathrm{P}<0.001$; Fig. 1B). In addition, the highest expression of miR-1266 in the HCC cell lines was in the MHCC97 cell line followed by the Huh-7 cell line (Fig. 1B). 

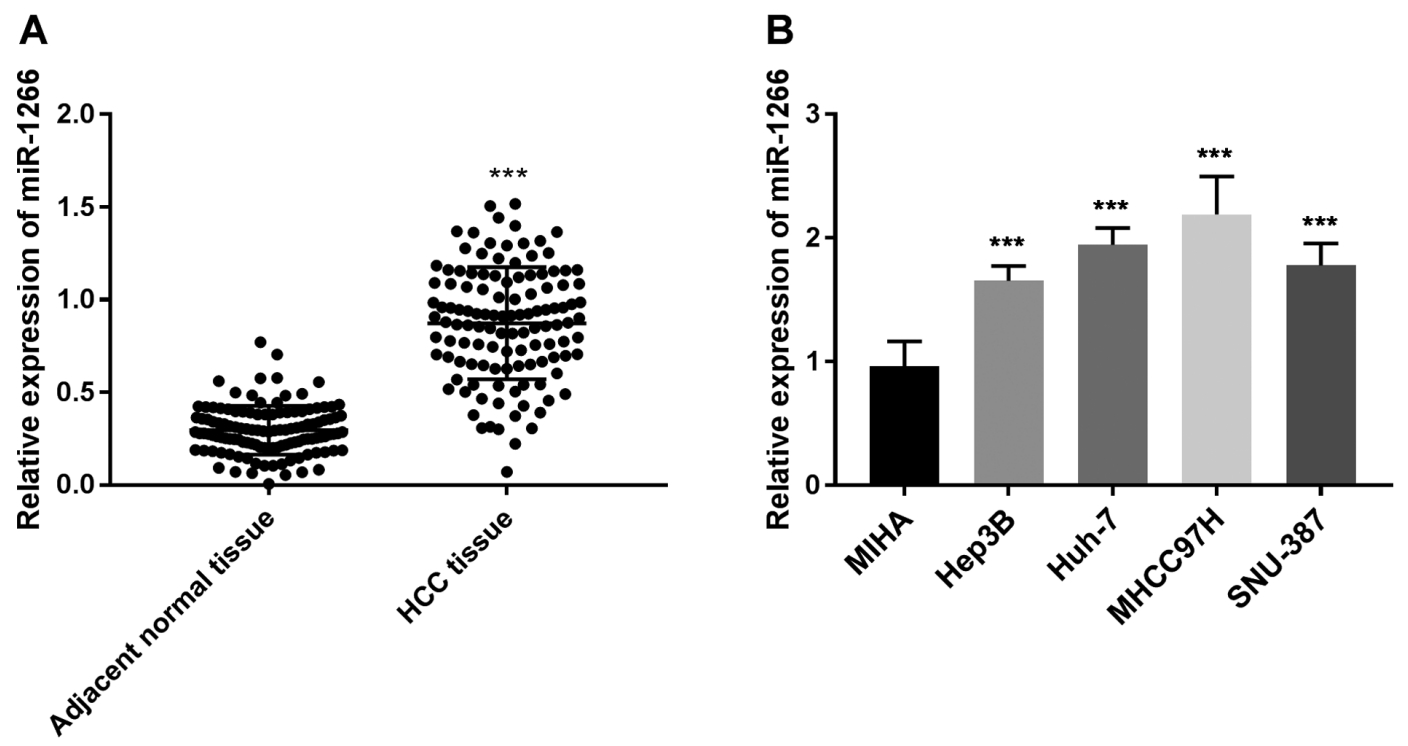

Figure 1. miR-1266 expression in HCC tissues and cell lines was detected using reverse transcription-quantitative PCR. (A) Relative expression of miR-1266 in HCC tissues and adjacent normal liver tissues from 119 patients. (B) Relative expression of miR-1266 in HCC cell lines (Hep3B, Huh-7, MHCC97 and SNU-387). ${ }^{* * *} \mathrm{P}<0.001$. HCC, hepatocellular carcinoma; miR, microRNA.

Hence, these 2 cell lines were selected for subsequent experimentation due to their high miR-1266 expression.

miR-1266 expression is associated with the clinicopathological features of patients with HCC. As shown in Table I, the association between miR-1266 expression and the clinicopathological characteristics of patients with HCC was assessed. The patients were divided into the miR-1266 low expression group $(n=57)$ and the miR-1266 high expression group $(n=62)$ with the mean value of miR-1266 expression as the cut-off value. The results demonstrated that high mRNA expression of miR-1266 was significantly associated with Tumor-Node-Metastasis (TNM) stage (28) ( $\mathrm{P}=0.014$; Table I). There was no significant association observed for the other characteristics, such as age, sex, hepatitis B virus infection, tumor size, AFP and cirrhosis ( $\mathrm{P}>0.05$; Table I).

High expression of miR-1266 is associated with poor prognosis in patients with HCC. To assess the potential prognostic value of using miR-1266 as a biomarker in HCC tissues, a cumulative survival curve was generated using the Kaplan-Meier method according to the patients' miR-1266 expression and overall survival information. The results demonstrated that, when compared with patients with lower miR-1266 expression levels, the 5-year survival rate of patients with HCC with higher miR-1266 expression levels was significantly lower (log-rank test $\mathrm{P}=0.015$; Fig. 2). In the multivariate Cox hazard regression model, further multivariate analysis of the association between miR-1266 expression levels and overall survival of patients with HCC was performed. The results demonstrated that the miR-1266 expression level [hazard ratio $(\mathrm{HR})=2.048$; $95 \%$ confidence interval $(\mathrm{CI})=1.151-3.664 ; \mathrm{P}=0.015$; Table II) and $\mathrm{TNM}$ stage $(\mathrm{HR}=1.900 ; 95 \% \mathrm{CI}=1.074-3.364 ; \mathrm{P}=0.028$; Table II) were independent prognostic factors for the 5-year overall survival of patients with HCC.

Overexpression of miR-1266 promotes HCC cell proliferation, migration, and invasion. To investigate whether miR-1266

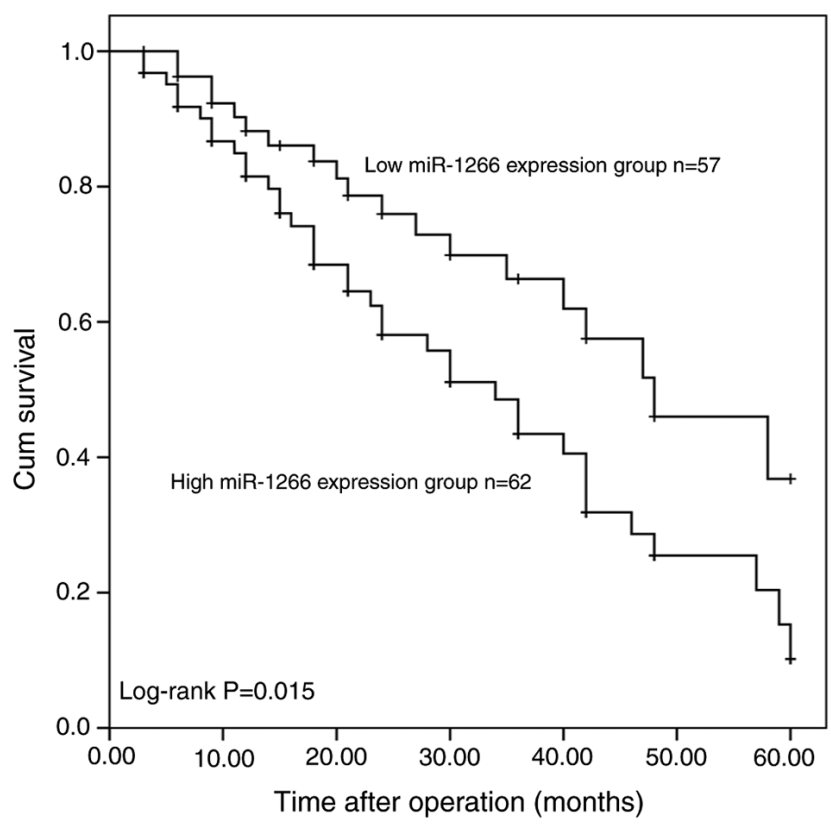

Figure 2. Kaplan-Meier survival curve of patients with HCC. The overall survival rate of patients with high expression of miR-1266 was lower compared with those with low expression. HCC, hepatocellular carcinoma; miR, microRNA.

regulates $\mathrm{HCC}$ cell proliferation, migration and invasion, in vitro $\mathrm{HCC}$ cell experiments were performed by transfecting miR-1266 mimics or miR-1266 inhibitor into MHCC97 and Huh7 cells. The effect of miR-1266 on the aforementioned cellular behavior was also measured in MIHA cells, which acted as a control for comparison with HCC cell lines. MHCC97 and Huh7 cells with significantly increased expression of miR-1266 $(\mathrm{P}<0.001)$ and MHCC97 and Huh7 cells with inhibited expression of miR-1266 were obtained through cell transfection, compared with untreated cells $(\mathrm{P}<0.01$; Fig. 3A). The CCK-8 cell proliferation assay demonstrated 
Table II. Multivariate Cox regression analysis for risk prognostic factors to the overall survival of patients with hepatocellular carcinoma.

\begin{tabular}{lccc}
\hline & \multicolumn{3}{c}{ Multivariate analysis } \\
\cline { 2 - 4 } Parameters & HR & $95 \% \mathrm{CI}$ & P-value \\
\hline miR-1266 expression & 2.048 & $1.151-3.644$ & 0.015 \\
Age & 1.149 & $0.641-2.058$ & 0.641 \\
Sex & 1.423 & $0.803-2.523$ & 0.227 \\
AFP & 1.175 & $0.674-2.048$ & 0.570 \\
Tumor size & 1.457 & $0.791-2.685$ & 0.227 \\
HBV infection & 1.583 & $0.888-2.822$ & 0.119 \\
Cirrosis & 2.011 & $0.960-4.212$ & 0.064 \\
TNM stage & 1.900 & $1.074-3.364$ & 0.028 \\
\hline
\end{tabular}

HCC, hepatocellular carcinoma; miR, microRNA; TNM, TumorNode-Metastasis; HBV, hepatitis B virus; AFP, $\alpha$-fetoprotein; $\mathrm{HR}$, hazard ratio; $\mathrm{CI}$, confidence interval.

that overexpression of miR-1266 by miR-1266 mimics in cells increased Transwell assays indicated that the migration and invasion of MHCC97 and Huh7 cells were significantly increased due to the overexpression of miR-1266 $(\mathrm{P}<0.001)$, while the downregulation of miR-1266 led to a significant decrease in the migration and invasion of MHCC97 $(\mathrm{P}<0.001)$ and Huh7 ( $\mathrm{P}<0.01)$ cells (Fig. 4A and B), however, no effect was observed in normal MIHA cell line (Fig. 4A and B). It can be seen from the images of MIHA, MHCC97 and Huh7 cells in Fig. S1A and B that the invasion and migration trends were consistent with those in Fig. 4A and B.

DAB2IP may be a direct target of miR-1266. Luciferase reporter assay was performed using MHCCH97 cells due to its superior cellular activities (proliferative, migratory, and invasive abilities) compared with Huh-7 cells. Based on the TargetScan database, position 996-1003 of DAB2IP mRNA 3'UTR was discovered to have binding sites of miR-1266 (Fig. 5A). Luciferase reporter gene detection was used to verify the effect of miR-1266 on DAB2IP in MHCCH97 cell because of its better cellular activities. miR-1266 mimics significantly reduced the relative luciferase activities of cells with wild miR-1266-binding site $(\mathrm{P}<0.001$; Fig. 5B) and miR-1266 inhibitors significantly increased its relative luciferase activities ( $\mathrm{P}<0.01$; Fig. 5B). However, neither miR-1266 mimics nor inhibitors caused significant changes in cells with mutated vectors (Fig. 5B). The aforementioned results demonstrated that miR-1266 can directly target DAB2IP expression.

\section{Discussion}

HCC is a disease that is common worldwide (29). The majority of patients find that the disease is already advanced upon diagnosis, and its prognosis is poor $(30,31)$. It is necessary to discover new and effective biomarkers for the diagnosis and prognosis of $\mathrm{HCC}$, which will help to improve the clinical efficacy of treatments in patients $(32,33)$. As a new type of biomarker, miRNAs serve an important role in the occurrence, development and metastasis of numerous types of cancer, such as HCC and prostate cancer $(34,35)$. Accumulating studies have investigated the association between cancer and miRNAs, and it has been proven that various cancers exhibit abnormal expression of miRNAs (36-38). For example, the low expression of miR-129 is significantly associated with the poor prognosis of prostate cancer, and can be regarded as a new molecular target for the diagnosis and treatment of prostate cancer (39). Wang et al (40) discovered that the expression of miR-339-5p is significantly reduced in HCC patients tissues compared with non-cancerous liver tissues, and is closely related to the invasion of $\mathrm{HCC}$ cells indicating that the expression of miR-339-5p is an independent prognostic factor in patients with HCC. Several studies have proven that the abnormal expression of miR-1266 serves an important role in various diseases and cancers, such as papillary thyroid carcinoma and prostate cancer (41-44).

miRNAs have been proven to be oncogenes in various cancers (45). Wang et al (44) confirmed that miR-1266 demonstrated a highly upregulated trend in the tissues and serum of patients with cervical cancer compared with the controls. The aforementioned study is consistent with the findings of the present study. In the present study, the expression of miR-1266 in HCC tissues and cell lines was examined, and its potential role in HCC was investigated in relation to the pathological characteristics of patients. The results demonstrated that the expression of miR-1266 was significantly increased in HCC tissues and cell lines compared with non-cancerous tissue and a normal cell line. In addition, in the present study high expression of miR-1266 demonstrated a significant association with TNM stage, which was consistent with other studies $(44,46)$. Lu et al (47) analyzed the miRNA expression profile of patients in The Cancer Genome Atlas database and concluded that miR-1266 is upregulated in HCC. The aforementioned results indicate that miR-1266 is an oncogene of $\mathrm{HCC}$ and is involved in the occurrence, development and metastasis of HCC.

In addition, the present study examined the relationship between miR-1266 expression and the survival of patients with HCC using Kaplan-Meier curves and Cox regression analysis. The present study found that high expression levels of miR-1266 reduced the 5-year overall survival rate of patients with HCC. In addition, it was found that the expression level of miR-1266 was an independent prognostic factor for 5-year overall survival. These results indicated that miR-1266 may be an important prognostic biomarker for HCC. Sevinc et al (42) proved that miR-1266 is associated with the recurrence and metastasis of estrogen receptor positive patients with breast cancer. Wang et al (44) revealed that the overall survival rate of patients with cervical cancer with high expression of miR-1266 was significantly lower compared with patients with low expression of miR-1266. These studies indicated that miR-1266 may be used as a new molecular target for the diagnosis and prognosis of cancer. However, a previous study did not find a significant association between miR-1266 expression and the clinical prognosis of HCC (47). This may be because the previous study (47) selected patients from TCGA database and the patients came from different hospitals in various cities and the time span was large, which may lead to inconsistent criteria for determining patient information. 

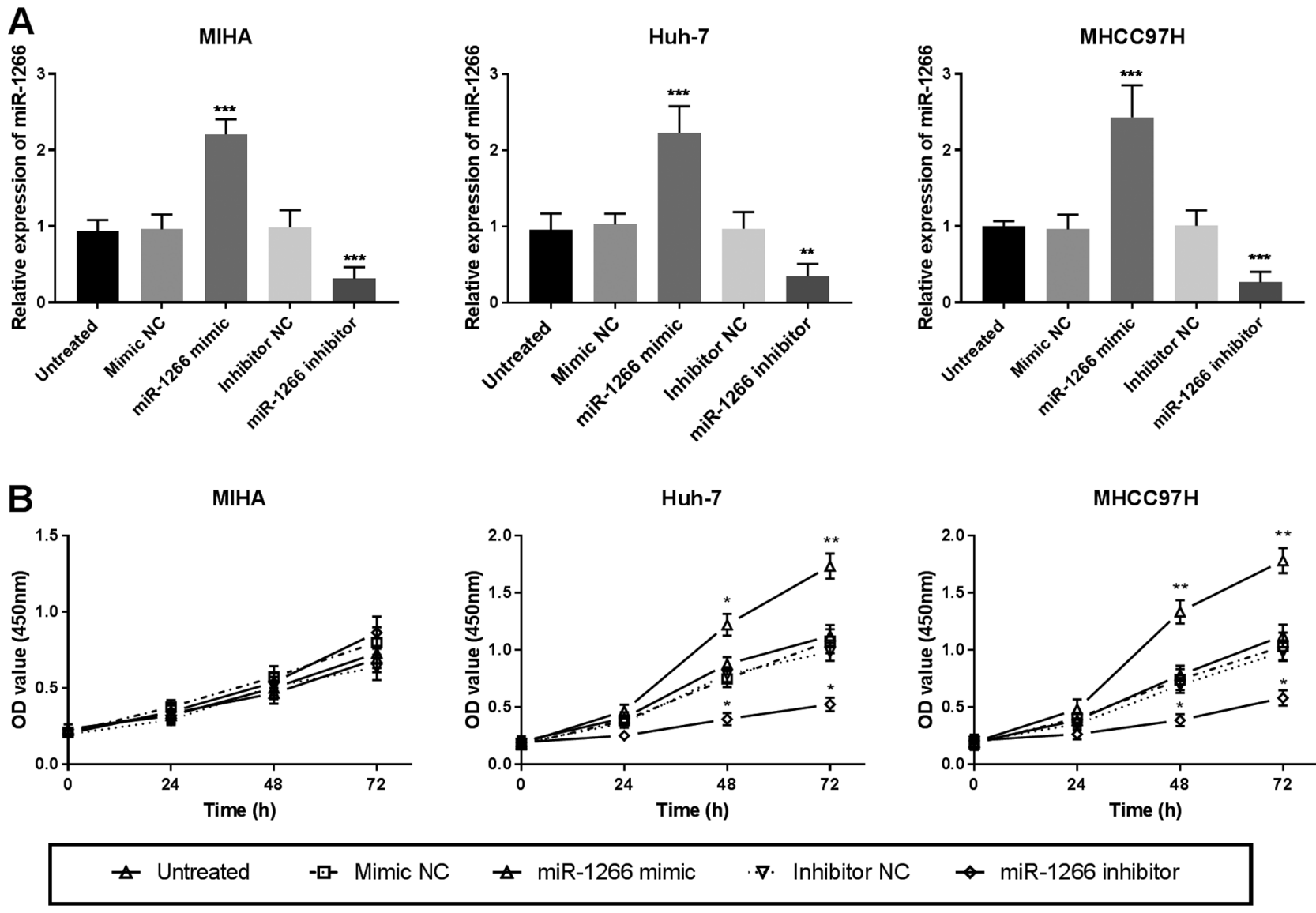

Figure 3. Effects of miR-1266 on proliferation of HCC cell lines. (A) Changes in the proliferation of MIHA, MHCC97 and Huh-7 cells following the transfection of miR-1266 mimics NC, miR-1266 mimic, inhibitor NC or miR-1266 inhibitor $\left({ }^{* *} \mathrm{P}<0.01,{ }^{* * *} \mathrm{P}<0.001\right)$ vs. untreated cells. (B) Effects of miR-1266 on the proliferation of MIHA, MHCC97 and Huh-7 cells $\left({ }^{*} \mathrm{P}<0.05,{ }^{* *} \mathrm{P}<0.01,{ }^{* * * *} \mathrm{P}<0.001\right)$ vs. untreated cells. HCC, hepatocellular carcinoma; miR, microRNA; NC, negative control; OD, optical density.

In addition, the present study investigated the effects of miR-1266 on the proliferation, migration and invasion of HCC cells using CCK-8 assays and Transwell assays, respectively. The results demonstrated that miR-1266 significantly increased the cell proliferation, migration and invasion ability of HCC cell lines, while inhibitors of miR-1266 inhibited their proliferation, migration and invasion. These results indicate that miR-1266 is involved in the molecular biological changes of HCC cells. Fu et al demonstrated that the upregulated expression of miR-1266 significantly inhibited the proliferation, migration and invasion of papillary thyroid carcinoma cells (41). Sun et al (43) revealed that overexpression of miR-1266 significantly attenuated the proliferation, migration and invasion of prostate cancer cell lines. Chen et al (48) confirmed that miR-1266 affected the proliferation and invasion of gastric cancer cells by targeting telomerase reverse transcriptase. These studies indicated that miR-1266 may participate in the occurrence and development of different diseases by affecting proliferation, migration and invasion, which is consistent with the findings of the present study.

Wang et al (44) proved that miR-1266 promoted proliferation, migration and invasion by targeting DAB2IP in HeLa and SiHa cells. Hence, the present study sought to investigate the interaction between miR-1266 and DAB2IP. The results revealed that the overexpression of miR-1266 directly targeted downregulation of DAB2IP. From the results of the present study it can be concluded that DAB2IP is a target gene of miR-1266 expressed in HCC tissues and cells. Previous studies have found that DAB2IP can be used as a target gene for regulating HCC. Liu et al (49) found that miR-328-5p decreased its expression by targeting DAB2IPmRNA and promoted the development of HCC. Chen et al (50) proved that there was a direct interaction between miR-1307-3p and the 3'UTR of DAB2IP, and miR-1307-3p served a driving role in the process of HCC by targeting DAB2IP. The results of the present study indicate that DAB2IP may be a target gene for miR-1266 serving a role in HCC cells. This speculation needs further investigation in future studies.

The lack of in vivo experiments was a limitation in the present study. The current study is relatively microscopic, and the lack of in vivo assays makes it impossible to observe the effects of miR-1266 expression on tumor growth and invasion from a macroscopic perspective. In future studies, in vivo assays should be performed in order to verify the findings of the present study and further investigate the role and mechanism of miR-1266 expression in vivo.

In conclusion, the results of the present study indicated that the expression of miR-1266 was significantly increased in patients with HCC and is associated with poor prognosis in patients, and promotes the proliferation, migration and invasion of HCC cells. The findings of the present study indicated that miR-1266 may be used as a biomarker for the prognosis of HCC. 
A

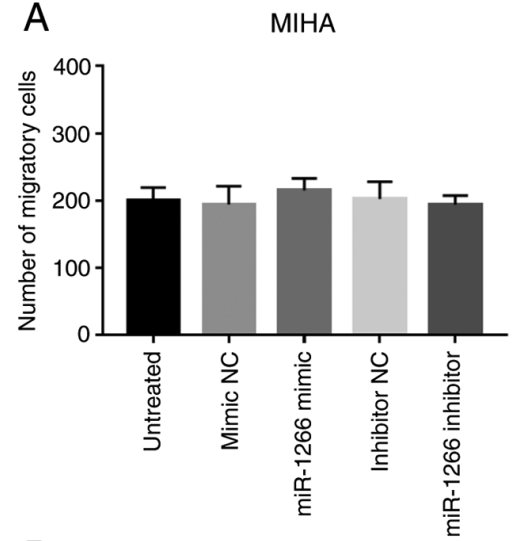

B

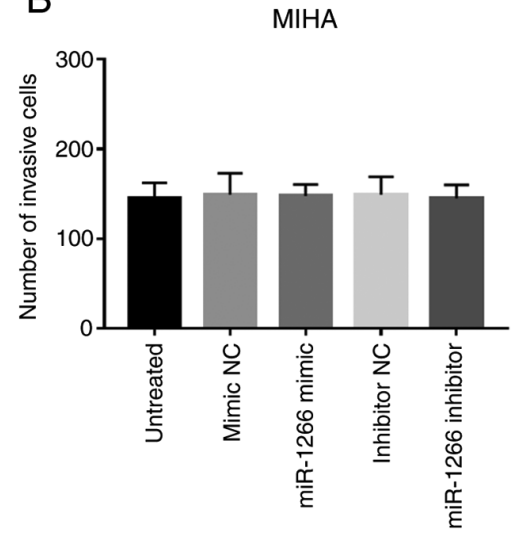

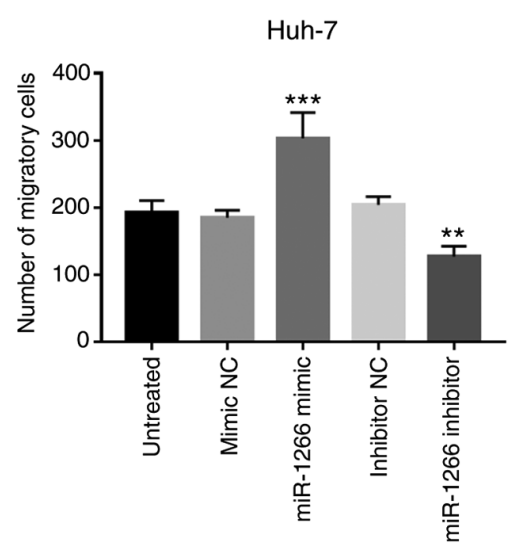

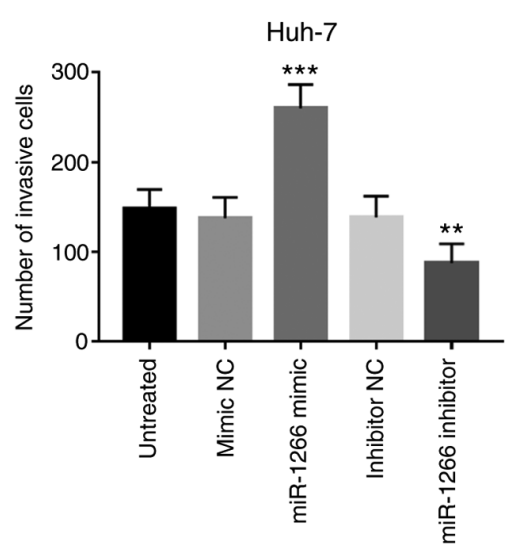

$\mathrm{MHCC} 97 \mathrm{H}$

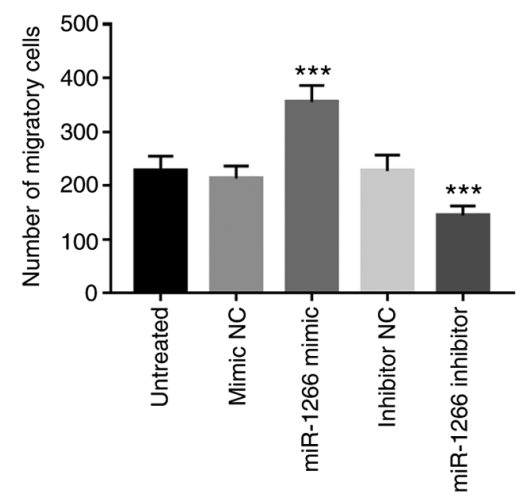

$\mathrm{MHCC} 97 \mathrm{H}$

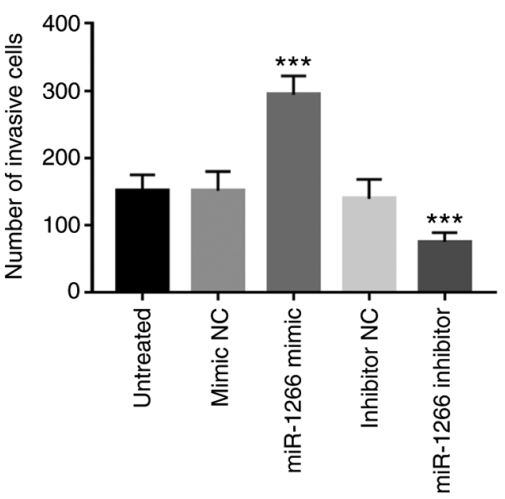

Figure 4. Effects of miR-1266 on migration and invasion of HCC cell line was performed using Transwell migration and invasion assays. (A) Effects of miR-1266 on the migration of MIHA, MHCC97 and Huh-7 cells. (B) Effects of miR-1266 on the invasion of MIHA, MHCC97 and Huh-7 cells. ("P $<0.01$, $\left.{ }^{* * * *} \mathrm{P}<0.001\right)$ vs. untreated cells. HCC, hepatocellular carcinoma; miR, microRNA; NC, negative control.

A

Position 996-1003 of DAB2IP 3'UTR (WT) 5'...CUGCAGGCCCUGAGA... miR-1266 3 3'...AGAUGUCGGGACUCC DAB2IP 3'UTR (MT) 5'...CUGCAGGGGGACUCA...

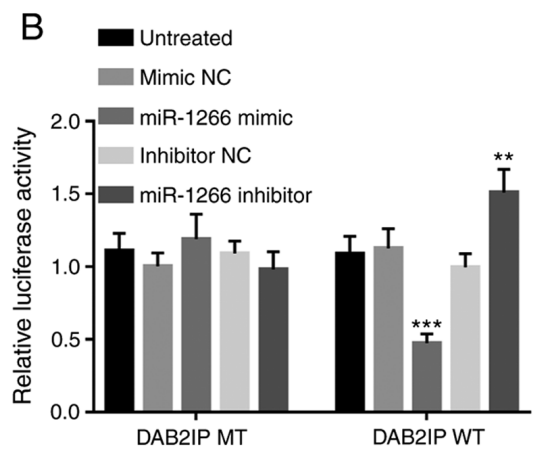

Figure 5. DAB2IP is the direct target gene of miR-1266. (A) Base complementarity between miR-1266 and DAB2IP was predicted using the Targetscan database. (B) Luciferase reporter gene determination. Following co-transfection with miR-1266 mimic and wild-type 3'-UTR-luciferase plasmid, luciferase activities decreased. $\left({ }^{* *} \mathrm{P}<0.01,{ }^{* * *} \mathrm{P}<0.001\right)$ vs. untreated cells. HCC, hepatocellular carcinoma; miR, microRNA; NC, negative control; WT, wild-type; MUT, mutant; 3'UTR, 3'-untranslated region; DAB2IP, DAB2 interacting protein.

\section{Acknowledgements}

Not applicable.

\section{Funding}

This study was supported by the Science Foundation of Fujian province (grant no. 2017J05144).

\section{Availability of data and materials}

The datasets used and/or analyzed during the current study are available from the corresponding author on reasonable request.

\section{Authors' contributions}

XH, YL, NY, YC, XY, ZC, YT, YH and JZ designed the study and performed the experiments. XH, YL and NY carried out the literature search, data acquisition, and data analysis. YC, $\mathrm{XY}, \mathrm{ZC}$ and YT provided assistance for data acquisition, data analysis and manuscript editing. XH, YL, NY, YC, and XY drafted the manuscript. $\mathrm{YH}$ and $\mathrm{JZ}$ revised the manuscript for important intellectual content. All authors read and approved the final manuscript.

\section{Ethics approval and consent to participate}

The present study was approved by the Research Ethics Committee of Mengchao Hepatobiliary Hospital of Fujian Medical University (approval no. 2012-032-01; Fuzhou, China). All patients signed a written consent approving the use of their tissues for research purposes after the operation. 


\section{Patient consent for publication}

Not applicable.

\section{Competing interests}

The authors declare that they have no competing interests.

\section{References}

1. Forner A, Llovet JM and Bruix J: Hepatocellular carcinoma. Curr Opin Gastroenterol 10: 339-351, 2006.

2. Heinrich B, Czauderna C and Marquardt JU: Immunotherapy of hepatocellular carcinoma. Oncol Res Treat 41: 292-297, 2018.

3. Etik DO, Suna N and Boyacioglu AS: Management of hepatocellular carcinoma: Prevention, surveillance, diagnosis, and staging. Exp Clin Transplant 31-35, 2017.

4. Intaraprasong P, Siramolpiwat S and Vilaichone RK: Advances in management of hepatocellular carcinoma. Asian Pac J Cancer Prev 17: 3697-3703, 2016

5. Sherman M: Recurrence of hepatocellular carcinoma. N Engl J Med 359: 2045-2047, 2008

6. Poon RTP: Differentiating early and late recurrences after resection of HCC in Cirrhotic Patients: Implications on Surveillance, prevention, and treatment strategies. Ann Surg Oncol 16: 792-794, 2009.

7. Cabrera R and Nelson DR: Review article: The management of hepatocellular carcinoma. Aliment Pharmacol Ther 31: 461-476, 2010.

8. Forner A, Da Fonseca LG, Diaz-Gonzalez A, SanduzziZamparelli M, Reig M and Bruix J: Controversies in the management of hepatocellular carcinoma. JHEP Rep 1: 17-29, 2019.

9. De Stefano F, Chacon E, Turcios L, Marti F and Gedaly R: Novel biomarkers in hepatocellular carcinoma. Dig Liver Dis 50 $1115-1123,2018$.

10. Awasthi R, Rathbone MJ, Hansbro PM, Bebawy M and Dua K: Therapeutic prospects of microRNAs in cancer treatment through nanotechnology. Drug Deliv Transl Res 8: 97-100, 2018.

11. Mohr AM and Mott JL: Overview of microRNA biology. Semin Liver Dis 35: 3-11, 2015.

12. Saliminejad K, Khorram Khorshid HR, Soleymani Fard S and Ghaffari SH: An overview of microRNAs: Biology, functions, therapeutics, and analysis methods. J Cell Physiol 234: 5451-5465, 2019.

13. Vienberg S, Geiger J, Madsen S and Dalgaard LT: MicroRNAs in metabolism. Acta Physiol (Oxf) 219: 346-361, 2017.

14. Cai Z, Zhang F, Chen W, Zhang J and Li H: miRNAs: A promising target in the chemoresistance of bladder cancer. Onco Targets Ther 12: 11805-11816, 2019.

15. Aghdam SG, Ebrazeh M, Hemmatzadeh M, Seyfizadeh N, Shabgah AG, Azizi G, Ebrahimi N, Babaie F and Mohammadi H: The role of microRNAs in prostate cancer migration, invasion, and metastasis. J Cell Physiol 234: 9927-9942, 2019.

16. Schulte C, Karakas M and Zeller T: microRNAs in cardiovascular disease-clinical application. Clin Chem Lab Med 55: 687-704, 2017.

17. Li C, Xu B, Miu X, Deng Z, Liao H and Hao L: Inhibition of miRNA-21 attenuates the proliferation and metastasis of human osteosarcoma by upregulating PTEN. Exp Ther Med 15: 1036-1040, 2018.

18. Garofalo M, Di Leva G, Romano G, Nuovo G, Suh SS, Ngankeu A, Taccioli C, Pichiorri F, Alder H, Secchiero P, et al: miR-221\&222 regulate TRAIL resistance and enhance tumorigenicity through PTEN and TIMP3 downregulation. Cancer Cell 16: 498-509, 2009.

19. Kong G, Zhang J, Zhang S, Shan C, Ye L and Zhang X Upregulated microRNA-29a by Hepatitis B Virus X protein enhances hepatoma cell migration by targeting PTEN in cell culture model. PLoS One 6: e19518, 2011.

20. Meng F, Henson R, Wehbe-Janek H, Ghoshal K, Jacob ST and Patel T: MicroRNA-21 regulates expression of the PTEN tumor suppressor gene in human hepatocellular cancer. Gastroenterology 133: 647-658, 2007.

21. Chen F, Li XF, Fu DS, Huang JG and Yang SE: Clinical potential of miRNA-221 as a novel prognostic biomarker for hepatocellular carcinoma. Cancer Biomark 18: 209-214, 2017.

22. Shi B, Zhang X, Chao L, Zheng Y, Tan Y, Wang L and Zhang W: Comprehensive analysis of key genes, microRNAs and long non-coding RNAs in hepatocellular carcinoma. FEBS Open Bio 8: 1424-1436, 2018
23. Aden DP, Fogel A, Plotkin S, Damjanov I and Knowles BB: Controlled synthesis of HBsAg in a differentiated human liver carcinoma-derived cell line. Nature 282: 615-616, 1979.

24. Nakabayashi H, Taketa K, Yamane T, Miyazaki M, Miyano K and Sato J: Phenotypical stability of a human hepatoma cell line, $\mathrm{HuH}-7$, in long-term culture with chemically defined medium. Gan 75: 151-158, 1984

25. Tian J, Tang ZY, Ye SL, Liu YK, Lin ZY, Chen J and Xue Q: New human hepatocellular carcinoma (HCC) cell line with highly metastatic potential (MHCC97) and its expressions of the factors associated with metastasis. Br J Cancer 81: 814-821, 1999.

26. Park JG, Lee JH, Kang MS, Park KJ, Jeon YM, Lee HJ, Kwon HS, Park HS, Yeo KS, Lee KU, et al: Characterization of cell lines established from human hepatocellular carcinoma. Int J Cancer 62: 276-282, 1995.

27. Livak KJ and Schmittgen TD: Analysis of relative gene expression data using real-time quantitative PCR and the 2(-Delta Delta C(T)) method. Methods 25: 402-408, 2001.

28. Cheng CH, Lee CF, Wu TH, Chan KM, Chou HS, Wu TJ, Yu MC, Chen TC, Lee WC and Chen MF: Evaluation of the new AJCC staging system for resectable hepatocellular carcinoma. World J Surg Oncol 9: 114, 2011.

29. Zachau L, Zeckey C, Schlue J, Sander J, Meyer-Heithuis C, Winkler M, Klempnauer J and Schrem H: Haematogenous abdominal wall metastasis of differentiated, alpha-fetoproteinnegative hepatocellular carcinoma after previous antiandrogen therapy within a site of lipoma manifestation since childhood. World J Surg Oncol 10: 98, 2012.

30. Poon RT and Fan ST: Hepatectomy for hepatocellular carcinoma: Patient selection and postoperative outcome. Liver Transpl 10 (2 Suppl 1): S39-S45, 2004.

31. Bray F, Ferlay J, Soerjomataram I, Siegel RL, Torre LA and Jemal A: Global cancer statistics 2018: GLOBOCAN estimates of incidence and mortality worldwide for 36 cancers in 185 countries. CA Cancer J Clin 68: 394-424, 2018.

32. Su CW, Lei HJ, Chau GY, Hung HH, Wu JC, Hsia CY, Lui WY, Su YH, Wu CW and Lee SD: The effect of age on the long-term prognosis of patients with hepatocellular carcinoma after resection surgery: A propensity score matching analysis. Arch Surg 147: 137-144, 2012

33. Xu RH, Wei W, Krawczyk M, Wang W, Luo H, Flagg K, Yi S, Shi W, Quan Q, Li K, et al: Circulating tumour DNA methylation markers for diagnosis and prognosis of hepatocellular carcinoma. Nat Mater 16: 1155-1161, 2017.

34. Sohn W, Kim J, Kang SH, Yang SR, Cho JY, Cho HC, Shim SG and Paik YH: Serum exosomal microRNAs as novel biomarkers for hepatocellular carcinoma. Exp Mol Med 47: e184, 2015.

35. Ostadrahimi S, Fayaz S, Parvizhamidi M, Abedi-Valugerdi M, Hassan M, Kadivar M, Teimoori-Toolabi L, Asgari M, Shahrokh H, Abolhasani M, et al: Downregulation of miR-1266-5P, miR-185-5P and miR-30c-2 in prostatic cancer tissue and cell lines. Oncol Lett 15: 8157-8164, 2018.

36. Cañueto J, Cardeñoso-Álvarez E, García-Hernández JL, Galindo-Villardón P, Vicente-Galindo P, Vicente-Villardón JL, Alonso-López D, De Las Rivas J, Valero J, Moyano-Sanz E, et al: MicroRNA (miR)-203 and miR-205 expression patterns identify subgroups of prognosis in cutaneous squamous cell carcinoma. Br J Dermatol 177: 168-178, 2017.

37. Zhang Y, Zhao Y, Sun S, Liu Z, Zhang Y and Jiao S: Overexpression of MicroRNA-221 is associated with poor prognosis in non-small cell lung cancer patients. Tumour Biol 37: 10155-10160, 2016.

38. Galardi S, Mercatelli N, Giorda E, Massalini S, Frajese GV, Ciafrè SA and Farace MG: miR-221 and miR-222 expression affects the proliferation potential of human prostate carcinoma cell lines by targeting p27Kip1. J Biol Chem 282: 23716-23724, 2007.

39. Xu S, Yi XM, Zhang ZY, Ge JP and Zhou WQ: miR-129 predicts prognosis and inhibits cell growth in human prostate carcinoma. Mol Med Rep 14: 5025-5032, 2016.

40. Wang YL, Chen CM, Wang XM and Wang L: Effects of miR-339-5p on invasion and prognosis of hepatocellular carcinoma. Clin Res Hepatol Gastroenterol 40: 51-56, 2016.

41. Fu YT,Zheng HB,Zhang DQ,Zhou L and Sun H: MicroRNA-1266 suppresses papillary thyroid carcinoma cell metastasis and growth via targeting FGFR2. Eur Rev Med Pharmacol Sci 22: 3430-3438, 2018

42. Sevinc ED, Egeli U, Cecener G, Tezcan G, Tunca B, Gokgoz S, Tasdelen I, Tolunay S and Evrensel T: Association of miR-1266 with recurrence/metastasis potential in estrogen receptor positive breast cancer patients. Asian Pac J Cancer Prev 16: 291-297, 2015. 
43. Sun CM, Zhang GM, Qian HN, Cheng SJ, Wang M, Liu M and Li D: MiR-1266 suppresses the growth and metastasis of prostate cancer via targeting PRMT5. Eur Rev Med Pharmacol Sci 23 : 6436-6444, 2019.

44. Wang J, Liu Y, Wang X, Li J, Wei J, Wang Y, Song W and Zhang Z: MiR-1266 promotes cell proliferation, migration and invasion in cervical cancer by targeting DAB2IP. Biochim Biophys Acta Mol Basis Dis 1864: 3623-3630, 2018.

45. Tutar Y: miRNA and cancer; computational and experimental approaches. Curr Pharm Biotechnol 15: 429, 2014

46. Zhang X, Ren D, Wu X, Lin X, Ye L, Lin C, Wu S, Zhu J, Peng X and Song L: miR-1266 contributes to pancreatic cancer progression and chemoresistance by the STAT3 and NF- $\kappa$ B signaling pathways. Mol Ther Nucleic Acids 11: 142-158, 2018.

47. Lu M, Kong X, Wang H, Huang G, Ye C and He Z: A novel microRNAs expression signature for hepatocellular carcinoma diagnosis and prognosis. Oncotarget 8: 8775-8784, 2017.
48. Chen L, Lü MH, Zhang D, Hao NB, Fan YH, Wu YY, Wang SM, Xie R, Fang DC, Zhang H, et al: miR-1207-5p and miR-1266 suppress gastric cancer growth and invasion by targeting telomerase reverse transcriptase. Cell Death Dis 5: e1034, 2014.

49. Liu Z, Yu Y, Huang Z, Kong Y, Hu X, Xiao W, Quan J and Fan X: CircRNA-5692 inhibits the progression of hepatocellular carcinoma by sponging miR-328-5p to enhance DAB2IP expression. Cell Death Dis 10: 900, 2019

50. Chen S, Wang L, Yao B, Liu Q and Guo C: miR-1307-3p promotes tumor growth and metastasis of hepatocellular carcinoma by repressing DAB2 interacting protein. Biomed Pharmacother 117: $109055,2019$. 